\title{
細線巻きつけによる水平管外凝縮の伝熱促進* （蒸気流速の影響に関する理論的検討）
}

\author{
王維 城**, 藤 井哲*** \\ Heat Transfer Enhancement for Condensation on \\ a Horizontal Tube by Coiling Wires \\ (Theoretical Consideration for Vapour Velocity Effect)
}

\author{
by Wei-Cheng WANG and Tetsu FUJII
}

\begin{abstract}
Numerical solutions are presented for combined shear- and gravity-controlled condensation on a horizontal tube, around which a fine wire is coiled, by using a simplified physical model. The local Nusselt number distribution represents that the effect of surface tension upon heat transfer decreases with the increase of vapour velocity. The average Nusselt number can be expressed by a rule of forth-power combination of the equations for shear-controlled condensation and gravity-controlled condensation. The heat transfer enhancement ratio against a smooth tube decreases with the increase of vapour velocity, because the decrease of effective heat transfer surface becomes more significant than the heat transfer enhancement due to surface tension. The Nu-equation for gravity-controlled condensation can be applicable in the velocity range where the heat transfer enhancement is achieved.
\end{abstract}

Key Words : Phase Change, Combined Shear- and Gravity- Controlled Condensation, Heat Transfer Enhancement, Horizontal Tube, Theory

\section{1. 緒}

前報(1)において水平円管上の体積力対流凝縮熱伝達 を，外面に細い線をコイル状に巻きつけることによっ て，促進する方法を提案した。 そして，理論解析と冷 媒 R11 およびエタノールを用いた実験とによって，細 線をその直径の 2 倍のピッチで巻いたとき最適であ り，平滑管に比して約 3 4 倍の熱伝達係数が得られ る場合があることを明らかにした。さらに，凝縮器内 部のすべての凝縮管上で体積力対流凝縮であり，かつ イナンデーションの悪影響もないと仮定すると、冷媒 の凝縮器については，伝熱面積を約 $1 / 2$ にし得るであ ろうと単純に推算した。

しかし，奉際の冷媒凝縮器の管群内では部分的に蒸 気流速が数 $\mathrm{m} / \mathrm{s}$ に達する.したがって, 凝縮器の設計 のためには，巻線の伝熱促進に及ぼす蒸気流速の影響 を明らかにしておく必要がある。本報では, 強制・体積 力共存対流凝縮を前報と同様な方法で理論的に解明す る.

・昭和 60 年 4 月 2 日 第 62 期通常総会講演会において講演, 原稿受付 昭和 59 年 10 月 26 日.

**正員, 清嚄大学熱能工程系 (中国北京市西爻清華圈).

… 正員，九州大学生産科学研究所（亚816 春日市春日公園 61).
はじめに主な記号を列挙する。

$$
\begin{aligned}
& C_{p} \text { : 定圧比熱 } \mathrm{J} /(\mathrm{kg} \cdot \mathrm{K}) \\
& D \text { : 伝熱管外径 } \mathrm{m} \\
& F_{r}: \text { フルード数 }=U_{\infty}^{2} / g D \\
& g: \text { 重力の加速度 } \mathrm{m} / \mathrm{s}^{2} \\
& G_{a}: \text { ガリレオ数 }=D^{3} \mathrm{~g} / \nu_{L}^{2} \\
& H: \text { 相変化数 }=C_{p L}\left(T_{s}-T_{w}\right) / L \\
& k: \text { 無次元数〔式 }(7)] \\
& L: \text { 凝縮の潜熱 } \mathrm{J} / \mathrm{kg} \\
& N_{u} \text { : 平均ヌセルト数〔式(25)] } \\
& N_{u B} \text { : 体積力対流凝縮の場合の平均ヌセルト数 } \\
& N_{u F} \text { ：強制対流凝縮の場合の平均ヌセルト数 } \\
& N_{u s} \text { : 平滑管の平均ヌセルト数 }
\end{aligned}
$$

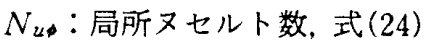

$$
\begin{aligned}
& P \text { : 圧力 } \mathrm{Pa} \\
& \bar{P}: \text { 無次元圧力〔式(13)) } \\
& p: \text { 紐線コイルのピッチ } \mathrm{m} \\
& P_{r}: \text { プラントル数 } \\
& R: \rho \mu \text { 比 }=\sqrt{\rho_{L} \mu_{L} / \rho \mu} \\
& R_{e}: \text { 二相レイノルズ数 }=U_{\infty} D / \nu_{L} \\
& r_{s} \text { : 液膜表面の曲率半径（図 I) } \mathrm{m} \\
& s: \text { 細線間の距離 } \mathrm{m} \\
& \vec{s} \text { : 無次元細線間距離 }=s / D
\end{aligned}
$$


1700

$T_{s}$ : 飽和蒸気温度 $\mathrm{K}$

$T_{w}$ ：伝熱管外表面温度 $\mathrm{K}$

$U_{\infty}:$ 蒸気の近奇り速度 $\mathrm{m} / \mathrm{s}$

$u, w: \phi お よ せ ゙ ~ z$ 方向速度 $\mathrm{m} / \mathrm{s}$

$y$ :管表面から外法線方向座標 $\mathrm{m}$

$z$ :管軸方向の座標 $\mathrm{m}$

$\bar{z}:$ 無次元管軸方向座標 $=z / D$

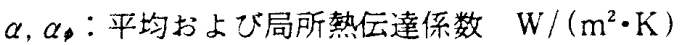

$\alpha^{*}, \beta^{*}, \gamma^{*}$ : 無次元数〔式 (17) (19)]

$\delta(\phi)$ : 液膜厚さ $\mathrm{m}$

$\bar{\delta}:$ 無次元液膜厚さ $=\delta / D$

$\lambda:$ 熱伝導率 $\mathrm{W} /(\mathrm{m} \cdot \mathrm{K})$

$\mu$ : 粘度 $\mathrm{Pa} \cdot \mathrm{S}$

$\nu$ : 動粘度 $\mathrm{m}^{2} / \mathrm{s}$

$\rho$ : 密度 $\mathrm{kg} / \mathrm{m}^{3}$

$\sigma:$ 表面張力 $\mathrm{N} / \mathrm{m}$

$\phi ：$ 管頂から測った角度座標

添字 $L$ は液膜，添字なしは蒸気の物性值を示す。

\section{2. 基 礎 式}

物理モデルと座標を図 1 に示す。前報(1)と異なると ころは重力方向に蒸気流速 $U_{\infty}$ があることである，基 礎式を導出する際の仮定，細線の近くの境界条件など は前報と同様であるので，重複をさけ，必要な部分の み再録する。

基礎式および境界条件は次のように書かれる。

$$
\begin{aligned}
& \mu_{L} \frac{\partial^{2} u}{\partial y^{2}}+\rho_{L} g \sin \phi=0 \quad(\phi \text { 方向運動 }) \cdots(1) \\
& \mu_{L} \frac{\partial^{2} w}{\partial y^{2}}-\frac{\partial P}{\partial z}=0 \quad(z \text { 方向運動 }) \cdots(2) \\
& \frac{2}{D} \frac{\partial}{\partial \phi} \int_{0}^{\pi} u d y+\frac{\partial}{\partial z} \int_{0}^{\pi} w d y=\frac{\lambda_{L}\left(T_{s}-T_{w}\right)}{\rho L \delta} \\
& y=0 \text { で } u=w=0 \cdots \cdots \cdots \cdots \cdots \cdots \cdots \cdots \cdots \cdots(3) \\
& y=\delta \text { 熱収支 }) \cdots \cdots \cdots \cdots \cdots \cdots \cdots \cdots \cdots(4)
\end{aligned}
$$

$\partial w / \partial y=0$

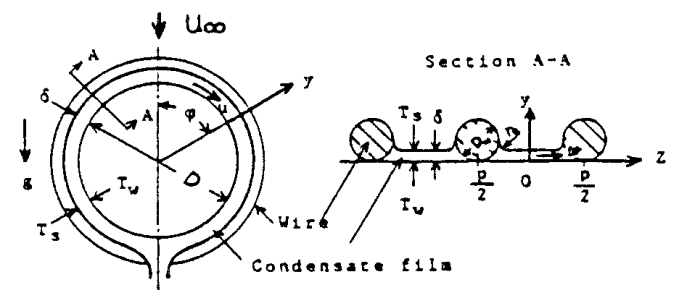

図1物理モデルと座標系
ここに

$$
k=\left(1+\frac{P_{r L}}{R H}\right)^{2: 3}
$$

式（5)は，主流がポテンシャル流れであり，気液界面 せん断力が凝縮質量流束に比例するという Shekriladze-Gomelauri ${ }^{(2)} の$ 考えに従ったものであ

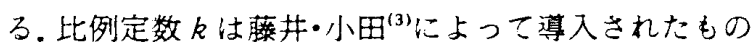
である。この方程式系は極端に単純化されたものであ るが，その解は，有機物質の水平平滑管上の凝縮につ いては，実測值に近い值を予測する(4).

前報と同様に，液膜が薄いので $\partial P / \partial z$ が $y$ の関数 ではないとみなして, 式(1)，(2)を条件式(4) 〜 (6)のもとに解くと，次式が得られる.

$$
\begin{aligned}
u & =\frac{\rho_{L} g}{\mu_{L}}\left(\delta y-\frac{y^{2}}{2}\right) \sin \phi \\
& +\frac{2 k \lambda_{L}\left(T_{s}-T_{w}\right) U_{\infty} \sin \phi}{\mu_{L} L \delta} y \\
w & =\frac{1}{\mu_{L}}\left(-\frac{\partial P}{\partial z}\right)\left(\delta y-\frac{y^{2}}{2}\right) \cdots \cdots
\end{aligned}
$$

式(8)，（9)を式(3)に代入し，無次元数を導入して 変形すると次式が得られる。

$$
\begin{gathered}
\frac{\partial}{\partial \phi}\left(\bar{\delta}^{3} \sin \phi\right)+\left(\frac{3 k H R_{e}}{P_{r L} G_{a}}\right) \frac{\partial}{\partial \phi}(\bar{\delta} \sin \phi) \\
-\frac{1}{2} \frac{\partial}{\partial \bar{z}}\left(\frac{\partial \vec{P}}{\partial \bar{z}} \bar{\delta}^{-3}\right)-\frac{3}{2} \frac{H}{P_{r L} G_{a} \bar{\delta}}=0 \cdots
\end{gathered}
$$

ここに

$$
\begin{aligned}
& \bar{\delta}=\frac{\delta}{D} \quad \cdots \\
& \bar{z}=\frac{z}{D} \cdots \\
& \bar{P}=\frac{P}{\rho_{L} g D}
\end{aligned}
$$

更に前報と同様に，次の条件

$$
\begin{aligned}
& \bar{z}=0 て \frac{\partial \bar{P}}{\partial \bar{z}}=0, \quad \bar{P}=0 \ldots \ldots \ldots \ldots \ldots \ldots \ldots \ldots \\
& \bar{z}=\frac{\bar{s}}{2} て\left(\frac{\partial \bar{P}}{\partial \bar{z}} \neq 0\right), \quad \bar{P}=-\frac{\sigma}{\rho_{L} g D r_{s}}
\end{aligned}
$$

のもとに式(10)を $\bar{z}$ に関して積分し, 変形すると, 次 式が得られる。

$$
\begin{aligned}
& \left(\frac{3}{2} \bar{\delta}^{2}+\frac{\gamma^{*}}{2}\right)(\sin \phi) \frac{d \bar{\delta}^{2}}{d \phi}+\left(\alpha^{*}+\cos \phi\right) \bar{\delta}^{4} \\
& +\gamma^{*}(\cos \phi) \bar{\delta}^{2}-\beta^{*}=0 \quad \cdots \cdots \ldots \ldots \ldots \ldots \ldots \ldots \ldots \ldots
\end{aligned}
$$

$こ こ に$

$$
\begin{aligned}
\alpha^{*} & =\frac{4 \sigma}{\bar{s}^{2} \rho_{L} g D r_{s}} \\
\beta^{*} & =\frac{3 H}{2 P_{r L} G_{a}} \cdots \\
\gamma^{*} & =\frac{3 k H R_{e}}{P_{r_{L}} G_{a}} \cdots
\end{aligned}
$$


境界条件は次式で与えられる。

$$
\phi=0 て ゙ \frac{d \bar{\delta}}{d \phi}=0
$$

式(16)において， $\alpha^{*} \rightarrow 0$ の場合が平滑管に相当す る.また，式(16)は $R_{e} \rightarrow 0$ および $G_{a} \rightarrow 0$ のとき，それ ぞれ次のようになる。

$$
\begin{gathered}
\frac{3}{2}(\sin \phi) \bar{\delta}^{-2} \frac{d \bar{\delta}^{2}}{d \phi}+\left(\alpha^{*}+\cos \phi\right) \delta^{4}-\beta^{*}=0 \\
\cdots \cdots \cdots \cdots(21 \\
\frac{1}{2}(\sin \phi) \frac{d \bar{\delta}^{2}}{d \phi}+\frac{\alpha^{*}}{\gamma^{*}} \bar{\delta}^{4}+(\cos \phi) \bar{\delta}^{2}-\frac{\beta^{*}}{\gamma^{*}}=0
\end{gathered}
$$

式(16)は, 特別の場合を除き,解析的には解けな い. $\phi=0$ および $\pi$ の極限の $\delta^{-2}$ は次の二次式を解くこ とによって求められる ( $\alpha^{*} \neq 0$ の場合).

$$
\left(\alpha^{*} \pm 1\right) \bar{\delta}^{4} \pm \gamma^{*} \bar{\delta}^{2}-\beta^{*}=0
$$

$\hat{\delta}^{2}=0$ を初期值として（例えば Adams 法で）式(16) を解くと， $\bar{\delta}^{2}(\phi)$ が求まる。 $\bar{\delta}^{2} \phi=\pi$ は数値解の精度の 検証として用いることができる.ただし， $\alpha^{*}=0$ の場 合は $\delta^{2}=\pi \rightarrow \infty$.

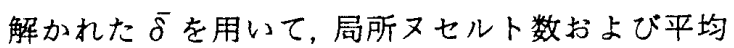
ヌセルト数は次式で計算できる.

$$
\begin{aligned}
& N_{u}=\frac{\alpha_{\phi} D}{\lambda_{L}}=\frac{1}{\delta(\phi)} \cdots \cdots . . \\
& N_{u}=\frac{\alpha D}{\lambda_{L}}=\frac{D_{s}}{\lambda_{L} p \pi} \int_{0}^{\pi} \alpha_{\phi} d_{\phi}
\end{aligned}
$$

\section{3. 数值解および考察}

次の条件を与えた場合の解を代表例として考察す る. 冷媒 $\mathrm{R} 11$ の飽和蒸気, $T_{s}=313 \mathrm{~K}, T_{s}-T_{w}=5 \mathrm{~K}$, $D=25.4 \mathrm{~mm}, s / p=0.5$, したがつて $G_{a} P_{r L} / H=3.63$ $\times 10^{11}, R_{e}=10^{5} U_{\infty}, k=2.1$.

図 2(a)〜 (c) はそれぞれ $R_{e}=10^{5}, 5 \times 10^{5}, 2 \times 10^{6}$, $\left(U_{\infty}=1,5,20 \mathrm{~m} / \mathrm{s}\right)$ )場合の $N_{u \phi}$ の分布を示す. 体積 力対流凝縮の場合 ${ }^{(1)}$ は $\alpha^{*}>15 て ゙ N_{u \triangleleft}$ が一様になり， $N_{u}=(s / p) N_{u \phi=0}$ とみなすことができた。しかし，図 2 においては， $\alpha^{*}=100$ においてもまだ一様分布にな っていない.そして， $U_{\infty}$ が大きいほど, $N_{u \triangleright}$ の周方向 変化は大きく, $\alpha^{*}=0$ の場合との差が小さい.このこ とは, 蒸気流速が増加すると, 表面張力の伝熱促進効 果が相対的に小さくなることを意味する，ただし，い ずれの図においても， $\alpha^{*}=0$ の場合の分布と比較する と, 後縁 $(\phi=\pi)$ に近づくとともに熱伝達の促進効果 が大きくなっていることがわかる。

図 3 は $N_{u} / \sqrt{R_{e}}$ と $P_{r L} / F_{r} H$ の関係を示す. $\alpha^{*}=0$ の場合の解 (X印) は次の藤井ら ${ }^{(5)}$ の式 (一点鎖線) と ほとんど一致している。

$$
\begin{aligned}
& \frac{N_{u s}}{\sqrt{R_{e}}}=\frac{\left(N_{u F}^{4}+N_{u B}^{4}\right)^{1.4}}{\sqrt{R_{e}}} \\
& \quad=\left\{1.30^{4}+0.725^{4}\left(\frac{P_{r L}}{F_{r} H}\right)\right\}^{1.4}
\end{aligned}
$$

$\alpha^{*}=100$ および 1000 の場合の解をそれぞれ。印およ びロ印で示す。蒸気流速が大きい $\left(P_{r L} / F_{r} H\right.$ が小さ い）ところで平滑管より低い值になるのは，細線巻き つけによる有効伝熱面積の隇少が表面張力による伝熱 促進効果より大きいことによる．

細線を巻きつけた場合の強制対流凝縮 $\left(R_{e} \rightarrow \infty\right)$ お よび体積力対流凝縮 $\left(R_{e} \rightarrow 0, \alpha^{*}>15\right)$ の場合の式はそ れぞれ次のようになる。

$$
\begin{aligned}
& N_{u F}=0.90\left(\frac{s}{p}\right) \sqrt{k} R_{e}^{1 / 2}=0.65 R_{e}^{1 / 2} \cdots \cdots \cdots(27) \\
& N_{u B}=1.246\left(\frac{s}{p}\right)\left\{0.725\left(\frac{G_{a} P_{r L}}{H}\right)^{1 / 4}\right\}\left(1+\alpha^{*}\right)^{1 / 4}
\end{aligned}
$$

式(26)と同様な四乗結合則がなりたつと仮定すると, 次式が得られる。
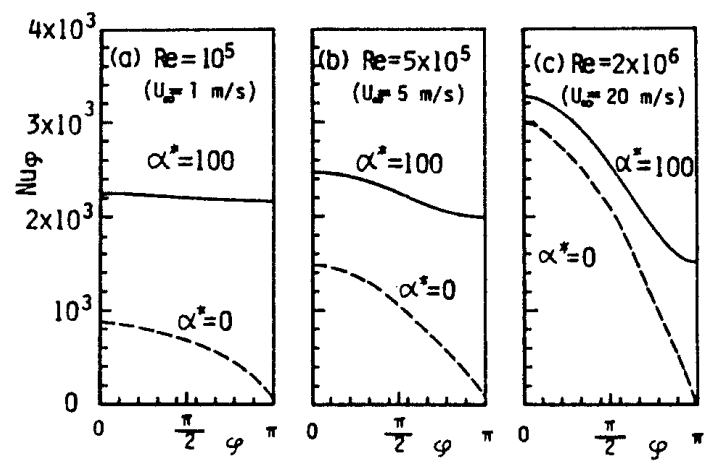

図 2 局所ヌ七ルト数

(R11 飽和蒸気， $G_{a} P_{r L} / H=3.63 \times 10^{11}, k=2.1$ )

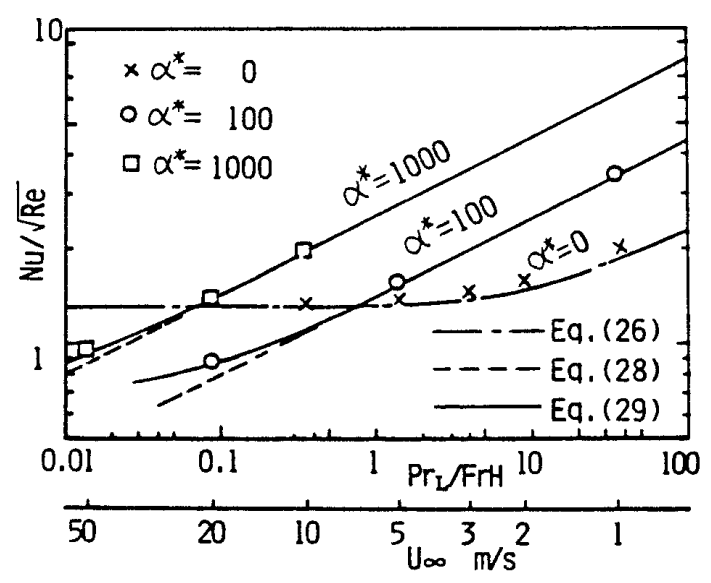

図 3 平均ヌセルト数 (R11, $G_{a} P_{r L} / H=3.63 \times 10^{11}, k=2.1, s / p=0.5$ ) 


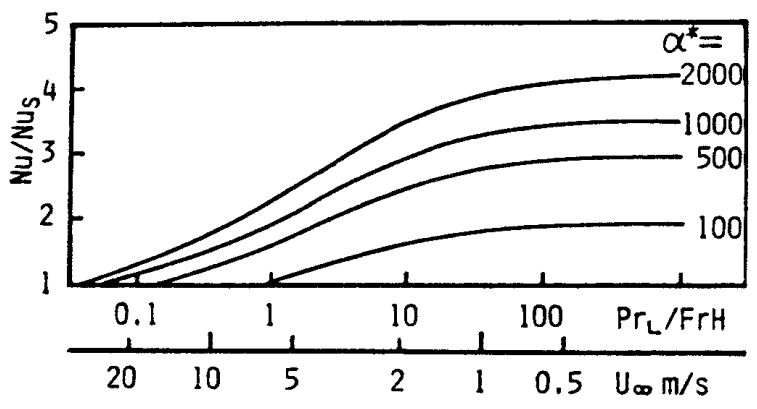

図 4 伝熱促進率

(R11, $\left.G_{a} P_{r L} / H=3.63 \times 10^{11}, k=2.1, s / p=0.5\right)$

$$
\frac{N_{u}}{\sqrt{R_{e}}}=\left\{0.65^{4}+0.452^{4}\left(1+\alpha^{*}\right) \frac{P_{r L}}{F_{r} H}\right\}^{1 / 4}
$$

図 3 に式(29)を実線で，式(28)を破線で示す。実線 と数值解とはよく一致している。なお， $N_{u}$ が平滑管よ り高い部分では，体積力対流凝縮の式(28)が適用でき る.

細線を巻きつけた場合の伝熱促進の程度は式(29)と 式(26)を比較することによって判断できる． $N_{u} / N_{u s}$ と $P_{r L} / F_{r} H$ の関係を $\alpha^{*}$ をパラメータとして図 4 に 示す。例えば， $r_{s}$ が体積力対流凝縮の場合と同じ式で 与えられると仮定し, 直径 $0.3 \mathrm{~mm}$ の線をピッチ 0.6 $\mathrm{mm}$ で巻きつけたとすれば， $\alpha^{*}=1100$ となる。

以上の議論俚特定の物性値を与えて， $\alpha^{*}$ のみをパ ラメータとして仮想的に変化させた例を用いて行われ た。しかし, 得られた基本的諸特性は異なる物性值の
組含せについてもなりたつ，蒸気流速が㱙に(したが つて $\alpha^{*}$ 汇)及涩す影響については，体積力刘流凝縮の 場合と同嵄に実験的に求めさるを得ないたろう。

\section{4. 結論}

単純化きれたモデルにより, 細線を巻きつけた水平 内管上の強制・体積力共存対流凝縮についての数值解 を求めた，局所ヌセルト数の特徵は，蒸気流速が高！ なると, 表面張力の効果が小さくなることを示す。平 均ヌセルト数は强制対流凝縮と体積力対流凝縮の式と の四乗結合則で精度よくあらわされる[式(29)]。

蒸気流速が高い場合は，有効伝熱面積の減少が表面 張力による伝熱促進効果を上まわり, 平均ヌセルト数 が平滑管の場合より小さくなる。そして, 平均ヌセル 卜数が平滑管のそれより高い $P_{r L} / F_{r} H$ の領域におい ては体積力対流㠜縮の式(28)を適用してょい.

\section{文献}

（1）薄茾・活か3名，第 62 期通常秷会講演会講演前刷，論文 No. 84-0386 A.

(2) Shekriladze, I. G. and Gomelauri, V. 1., Int. J. Heat Mass Transf., 9-6 (1966), 581.

（3）藤夰・小田，第21 回伝熟シンポジウム講演論文集，(昭 59), 298.

(4) Lee, W. C. and Rose, J. W., Proc. 7th Int. Heat Transf. Conf., Munich, Germany, 5 (1982), 101.

（5）藤井・ほか2 名，㙨論，37-294（昭 46），364。 